\title{
Quality of mitral valve repair: Median sternotomy versus port-access approach
}

\author{
Ehud Raanani, MD, Dan Spiegelstein, MD, Leonid Sternik, MD, Sergey Preisman, MD, \\ Yaron Moshkovitz, MD, Aram K. Smolinsky, MD, and Amihai Shinfeld, MD
}

\begin{abstract}
Objectives: We sought to compare early and late clinical and echocardiographic outcomes of patients undergoing minimally invasive mitral valve repair by means of the port-access and median sternotomy approaches.
\end{abstract}

\begin{abstract}
Methods: Between 2000 and 2009, 503 patients had mitral valve repair, of whom 143 underwent surgical intervention for isolated posterior leaflet pathology: 61 through port access and 82 through median sternotomy. The port-access group had better preoperative New York Heart Association functional class $(P=.007)$ and a higher rate of elective cases $(97 \%$ vs $87 \%, P=.037)$. Other preoperative characteristics were similar between the groups, including mitral valve pathology and repair techniques.
\end{abstract}

Results: Operative, bypass, and clamp times were significantly longer in the port-access group. Mean hospital stay was $5.3 \pm 2.5$ days in the port-access group versus $5.7 \pm 2.5$ days in the median sternotomy group $(P=.4)$. Early postoperative echocardiographic analysis showed that most patients in both groups had none or trivial mitral regurgitation and none of the patients had greater than grade 2 mitral regurgitation. Follow-up extended for up to 100 months (mean, $34 \pm 24$ months). New York Heart Association class improved in both groups $(P=.394)$. Freedom from reoperation was $97 \%$ and $95 \%$ in the port-access and median sternotomy groups, respectively. Late echocardiographic analysis revealed that $82 \%(49 / 60)$ in the port-access group and $91 \%(73 / 80)$ in the median sternotomy group were free from moderate or severe mitral regurgitation $(P=.11)$.

Conclusions: In isolated posterior mitral valve pathology, quality of mitral valve repair with the port-access approach can compare with that with the conventional median sternotomy approach. (J Thorac Cardiovasc Surg 2010;140:86-90)

A better understanding of the structure, function, and pathology of the mitral valve (MV) has led to improved surgical results of MV repair, with early mortality reduced to less than $1 \%$, excellent long-term durability, and patient survival. ${ }^{1-5}$

Efforts to minimize surgical trauma, hasten patient recovery, improve cosmetics, and increase patient satisfaction continue to motivate minimally invasive procedures. Although several approaches have been advocated for MV surgery, ${ }^{6-11}$ some have expressed concern that minimally invasive techniques might lead to inferior results, particularly regarding MV repair. Such concerns are based on the fact that operative space is limited and "operator to MV", distance is extended during a minimally invasive approach. Smaller incisions are more attractive to patients, but the quality of MV repair must not be compromised by the motivation to develop and market new techniques in response to patient expectations.

From the Department of Cardiac Surgery, Chaim Sheba Medical Center, Tel Hashomer, affiliated with the Sackler School of Medicine, Tel-Aviv University, Tel Aviv, Israel.

Disclosures: None.

Received for publication July 13, 2009; revisions received Sept 2, 2009; accepted for publication Sept 17, 2009; available ahead of print Dec 7, 2009.

Reprint requests: Ehud Raanani, MD, Department of Cardiac Surgery, Chaim Sheba Medical Center, Tel Hashomer, 52621, Israel (E-mail: ehud.raanani@sheba. health.gov.il).

$0022-5223 / \$ 36.00$

Copyright (c) 2010 by The American Association for Thoracic Surgery doi:10.1016/j.jtcvs.2009.09.035
Several studies have documented excellent clinical outcomes for minimally invasive approaches, and a systematic review of the literature with a meta-analysis of all important series has recently been published. ${ }^{12}$ Although this review described some studies on the incidence of long-term freedom from reoperation, none of the studies demonstrated the longterm effects on the quality of MV repair, including full echocardiographic follow-up of the repaired MV compared with results of the conventional median sternotomy (MS) approach. One study ${ }^{13}$ has reported excellent early and 1-year echocardiographic results of MV repair for the minimally invasive approach. However, this study was limited by a 1-year follow-up without comparison with an MS group.

In this study we analyzed and compared data for both early and late clinical and echocardiographic outcomes of patients undergoing minimally invasive MV repair through the port-access (PA) and MS approaches.

\section{MATERIALS AND METHODS}

This is a retrospective nonrandomized review of a prospective follow-up of all patients who underwent primary isolated MV repair for isolated posterior leaflet pathology through either a video-assisted right minithoracotomy (PA approach) or full MS (MS approach).

\section{Patients}

Between June 2000 and March 2009, 503 patients underwent MV repair in our department. Throughout that time, a total of 169 PA minimally invasive procedures were performed (eg, MV replacement, MV repair, tricuspid 


$$
\begin{aligned}
& \text { Abbreviations and Acronyms } \\
& \begin{aligned}
\text { MR } & =\text { mitral regurgitation } \\
\text { MS } & =\text { median sternotomy } \\
\text { MV } & =\text { mitral valve } \\
\text { NYHA } & =\text { New York Heart Association } \\
\text { PA } & =\text { port access }
\end{aligned}
\end{aligned}
$$

valve surgery, atrial septal defect closure, and myxoma excision). The study comprised all consecutive patients who had undergone isolated repair of the posterior MV leaflet. Patients with other valve pathologies or previous cardiac surgeries or those who had undergone concomitant procedures (eg, coronary artery bypass grafts, other valves, and the maze procedure) were excluded. Based on these criteria, 143 patients were included in the study, 61 of whom underwent surgical intervention through the PA approach and 82 through the conventional MS approach. The PA group had better preoperative New York Heart Association (NYHA) functional class $(P=.007)$ and a higher rate of elective cases $(97 \%$ vs $87 \%, P=.037)$. Other preoperative characteristics were similar between the groups (Table 1). Patient selection for the MS or PA approach was based on patient and surgeon preference.

\section{Surgical Techniques}

MS. Patients in the MS group underwent surgical intervention through a standard MS incision with conventional cardiopulmonary bypass with ascending aortic and bicaval cannulation. Intermittent cold blood cardioplegia was administrated through the aortic root and coronary sinus. A traditional left atrial incision, parallel to the interatrial sulcus, was used to access the MV. The incision was started from the superior vena cava and extended inferiorly to the mitral annulus. The most common valve repair procedure was triangular resection and primary closure of the resected portion of the posterior leaflet with 2 continuous layers of 4-0 Prolene sutures (Ethicon, Inc, Somerville, NJ). In the past, we used artificial chords for posterior repair only in cases of fibroelastic deficiency. Recently, we have also been using them for myxomatous posterior pathology.

The repair was completed with annuloplasty by using a flexible posterior band in $41(50 \%)$ of 82 patients, a complete semirigid ring in $33(40 \%)$ of 82 patients, and other types of annuloplasty in $8(10 \%)$ of 82 patients.

PA. For the PA approach, patients were placed in a supine position with slight elevation of the right hemithorax and intubated with a double-lumen endotracheal tube. External defibrillator patches were placed on the thoracic cage, and a $17 \mathrm{~F}$ or $19 \mathrm{~F}$ cannula was inserted through the right jugular vein into the superior vena cava. A 6- to 8-cm skin incision was made in the right inframammary groove to create a small anterolateral "working port." A soft tissue retractor (Heartport; Edwards Lifesciences, Irvine, Calif) was placed in the incision.

After switching to single left lung ventilation, 3 thoracic ports were created. The first port $(5 \mathrm{~mm})$, for video assistance with an endoscopic camera, was located in the fourth intercostal space at the level of the anterior axillary line. The second port $(5 \mathrm{~mm})$, for placing the left atrial retractor rod, was located parasternally in the fourth intercostal space. The third port was made below the incision for placing a left ventricular vent.

After general heparinization, arterial and venous cannulas were inserted by using the Seldinger technique in the right groin through a 2- to 3-cm-long incision covered by the natural skin folds of the groin. Arterial and venous cannulas were introduced over a guidewire under transesophageal echocardiographic control, and an EndoClamp balloon (Ethicon, Inc) was positioned at the ascending aorta just above the sinotubular junction. The cardiopulmonary bypass protocol included a membrane oxygenator, roller pump, and assisted venous return. The patient was cooled to a body temperature of $28^{\circ} \mathrm{C}$ to $30^{\circ} \mathrm{C}$. After aortic occlusion, antegrade cold blood cardioplegia was delivered through the balloon tip and repeated every 30 minutes. Aortic crossclamping was done with an EndoClamp balloon in 43 cases and a transthoracic Chitwood clamp (Scanlan International, St. Paul, Minn) in 18 cases.

Traditional left atrial incision parallel to the interatrial sulcus was used to approach the MV, and the left atrial retractor was placed through the parasternal incision at the fourth intercostal space. As in the MS group, the most common repair in the PA group was triangular resection and primary closure of the resected portion of the posterior leaflet with a Prolene 4-0 suture. In the past, we used artificial chords for posterior repair only in cases of fibroelastic deficiency. Recently, we have also been using them for myxomatous posterior pathology. The repair was completed with annuloplasty by using a flexible posterior band in $33(54 \%)$ of 61 patients, a complete semirigid ring in $23(38 \%)$ of 61 patients, and other types of annuloplasty in $5(8 \%)$ of 61 patients. In the early stage of the PA group, the Alfieri edge-to-edge technique was used as part of the repair in 6 patients. In 4 patients it was chosen by the surgeon as part of the repair technique and in 2 patients as a bailout procedure to minimize operative time when the intraoperative echocardiographic result was unsatisfactory.

\section{Follow-up}

Demographic, echocardiographic, and surgical data were collected from our prospectively collected database, whereas mortality data were retrieved from the official national database. All patients were contacted for clinical follow-up. Late follow-up echocardiographic data were obtained from the institutional echocardiographic laboratory database or from ambulatory medical services.

\section{Data Analysis}

The data for this review were derived from the database of the cardiac surgery department and have the approval of the institutional review board. Complications were reported according to the "Guidelines for reporting mortality and morbidity after cardiac valve interventions." ${ }^{, 14}$ Mitral regurgitation (MR) grade was classified according to Society of Thoracic Surgeons guidelines (http://www.sts.org/file/CoreDef241Book.pdf): grade 0, no MR; grade 1, trivial MR; grade 2, mild MR; grade 3, moderate MR; and grade 4 , severe MR.

All statistical analyses were performed with SPSS software (SPSS 16.0 for Windows; SPSS, Inc, Chicago, Ill). Group statistics were expressed as means $\pm 1 \mathrm{SD}$. Continuous variables were compared by using Student's $t$ test, and categorical variables were compared by using the $\chi^{2}$ test. Predictors for increased operative risks were determined by means of multivariate analysis. Survival information for the 2 groups was compared by using KaplanMeier curves with the log-rank test.

\section{RESULTS \\ Early Results}

Surgical information is summarized in Table 2. MV repair techniques were similar between the groups, except for the use of the Alfieri edge-to-edge technique, which was more common in the early stage of the PA group (6 patients). There was no conversion from minithoracotomy to MS in the PA group. Mean operative, cardiopulmonary, and aortic clamp times were significantly longer in the PA group compared with those in the MS group $(P<.001$, Table 2$)$.

No operative or in-hospital mortality occurred in either group. Freedom from major hospital morbidity (including stroke, transmural myocardial infarction, re-exploration for bleeding or tamponade, renal failure, respiratory failure, sepsis, and deep wound infection) was similar between the groups (PA group, $85 \%$; MS group, $92 \% ; P=.233$; Table 3 ). 
TABLE 1. Patients' characteristics

\begin{tabular}{lccc}
\hline \multicolumn{1}{c}{ Characteristic } & $\begin{array}{c}\text { Port-access } \\
\text { approach }\end{array}$ & $\begin{array}{c}\text { Median sternotomy } \\
\text { approach }\end{array}$ & $\begin{array}{c}\boldsymbol{P} \\
\text { value }\end{array}$ \\
\hline $\begin{array}{l}\text { No. of patients } \\
\text { Age (y) }\end{array}$ & 61 & 82 & \\
Sex & $55 \pm 11$ & $57 \pm 12$ & .349 \\
$\quad$ Male & $54(88.5 \%)$ & $62(76 \%)$ & \\
$\quad$ Female & $7(11.5 \%)$ & $20(24 \%)$ & .051 \\
Preoperative NYHA class & & & \\
I & $29(47 \%)$ & $19(23 \%)$ & .007 \\
II & $15(25 \%)$ & $33(40 \%)$ & \\
III & $17(28 \%)$ & $23(28 \%)$ & \\
IV & 0 & $7(9 \%)$ & \\
Timing & & & \\
$\quad$ Elective & $59(97 \%)$ & $71(87 \%)$ & .037 \\
$\quad$ Urgent & $2(3 \%)$ & $11(13 \%)$ & .84 \\
AF/PAF & $4(7 \%)$ & $5(6 \%)$ & \\
\hline NYHA, New York Heart Association; $A F$, atrial fibrillation; $P A F$, paroxysmal atrial fi- \\
brillation.
\end{tabular}

Freedom from any in-hospital morbidity was lower in the PA group (54\% vs $69 \%$ in the MS group, $P=.074)$. This was mainly attributed to a higher level of minor pulmonary complications, such as pulmonary atelectasis or partial right diaphragm elevation (10 [16\%] patients in the PA group vs 2 $[2 \%]$ patients in the MS group, $P=.003$ ) and a higher rate of superficial wound infection in the PA group (7\%) compared with that seen in the MS group ( $2 \%)$. However, none of these patients had any respiratory compromise or required any medical intervention, and all were discharged by day 5 or 6. No aortic dissection or injury occurred in either group.

Early postoperative echocardiographic results were as follows: $67 \% / 47 \%$ had no MR (grade 0 ), $22 \% / 30 \%$ had minimal MR (grade 1), $8 \% / 21 \%$ had mild MR (grade 2), and

TABLE 2. Operative data

\begin{tabular}{lccr}
\hline & $\begin{array}{c}\text { Port access } \\
(\mathbf{n}=\mathbf{6 1})\end{array}$ & $\begin{array}{c}\text { Median sternotomy } \\
(\mathbf{n}=\mathbf{8 2})\end{array}$ & $\boldsymbol{P}$ value \\
\hline Operative time (min) & $334 \pm 109$ & $190 \pm 88$ & $<.001$ \\
Extracorporeal circulation & $144 \pm 27$ & $81 \pm 21$ & $<.001$ \\
$\quad$ time (min) & & & \\
Crossclamp time (min) & $101 \pm 19$ & $61 \pm 16$ & $<.001$ \\
Annuloplasty & $61(100 \%)$ & $82(100 \%)$ & \\
$\quad$ Flexible posterior band & $33(54 \%)$ & $41(50 \%)$ & .758 \\
$\quad$ Complete semirigid ring & $23(38 \%)$ & $33(40 \%)$ & .758 \\
$\quad$ Other & $5(8 \%)$ & $8(10 \%)$ & .758 \\
Posterior leaflet resection & $46(75 \%)$ & $66(80 \%)$ & .466 \\
Alfieri edge-to edge repair & $6(10 \%)$ & $1(1 \%)$ & .018 \\
Artificial chordae & $16(26 \%)$ & $27(33 \%)$ & .388 \\
Aortic clamp & & & \\
$\quad$ Standard clamp & 0 & 82 & \\
EndoClamp balloon & $43(70 \%)$ & - & \\
$\quad$ Chitwood transthoracic & $18(30 \%)$ & - & \\
$\quad$ clamp & & & \\
\hline
\end{tabular}

TABLE 3. In-hospital and follow-up data

\begin{tabular}{|c|c|c|c|}
\hline & $\begin{array}{l}\text { Port access } \\
(n=61)\end{array}$ & $\begin{array}{l}\text { Median sternotomy } \\
\quad(\mathbf{n}=\mathbf{8 2})\end{array}$ & $\begin{array}{c}P \\
\text { value }\end{array}$ \\
\hline Hospital mortality & 0 & 0 & \\
\hline \multicolumn{4}{|l|}{ Complications } \\
\hline $\begin{array}{l}\text { Revision for bleeding/ } \\
\text { tamponade }\end{array}$ & $2(3 \%)$ & $2(2 \%)$ & .763 \\
\hline $\begin{array}{l}\text { Cardiac events } \\
\text { (low cardiac output, } \\
\text { perioperative MI) }\end{array}$ & $1(2 \%)$ & $3(4 \%)$ & .469 \\
\hline CVA/TIA & $3(5 \%)$ & $4(5 \%)$ & .991 \\
\hline Diaphragm elevation & $5(8 \%)$ & 0 & .008 \\
\hline Pulmonary complications* & $5(8 \%)$ & $2(2 \%)$ & .115 \\
\hline $\begin{array}{l}\text { Postpericardiotomy } \\
\text { syndrome }\end{array}$ & $7(11.5 \%)$ & $2(2 \%)$ & .028 \\
\hline Acute renal failure & $2(3 \%)$ & $2(2 \%)$ & .763 \\
\hline $\begin{array}{r}\text { Wound infection } \\
\text { (superficial) }\end{array}$ & $4(7 \%)$ & 0 & .019 \\
\hline Thorax & $2(3 \%)$ & 0 & .099 \\
\hline Groin & $2(3 \%)$ & 0 & .099 \\
\hline $\begin{array}{l}\text { Freedom from } \\
\text { any complication }\end{array}$ & $33(54 \%)$ & $57(69 \%)$ & .074 \\
\hline $\begin{array}{l}\text { Freedom from major } \\
\text { hospital morbidity } \dagger\end{array}$ & $52(85 \%)$ & $76(92 \%)$ & .233 \\
\hline Hospital duration (d) & $5.3 \pm 2.5$ & $5.7 \pm 2.5$ & .451 \\
\hline Mean follow-up (mo) & $41 \pm 24$ & $28 \pm 22$ & .002 \\
\hline Late mortality & 0 & $3(4 \%)$ & .133 \\
\hline $\begin{array}{l}\text { Freedom from reoperation at } \\
\text { follow-up }\end{array}$ & $59(97 \%)$ & $78(95 \%)$ & .637 \\
\hline Infective endocarditis & $1(2 \%)$ & $1(2 \%)$ & .989 \\
\hline $\mathrm{EF}(\%)$ at follow-up & $57 \pm 8$ & $57 \pm 5$ & .894 \\
\hline \multicolumn{4}{|l|}{ NYHA class at follow-up } \\
\hline I & $44(72 \%)$ & $48(61 \%)$ & .394 \\
\hline II & $10(16 \%)$ & $19(25 \%)$ & \\
\hline III & $7(12 \%)$ & $10(13 \%)$ & \\
\hline IV & 0 & $1(1 \%)$ & \\
\hline Mean MR at follow-up $\ddagger$ & $1.52 \pm 0.97$ & $1.2 \pm 0.89$ & .071 \\
\hline $\begin{array}{l}\text { MR grade 0/1 (no/trivial } \\
\text { MR) }\end{array}$ & $25(42 \%)$ & $43(54 \%)$ & \\
\hline MR grade 2 (mild MR) & $24(40 \%)$ & $30(37 \%)$ & \\
\hline MR grade 3 (moderate MR) & $9(15 \%)$ & $2(3 \%)$ & \\
\hline MR grade 4 (severe MR) & $2(3 \%)$ & $5(6 \%)$ & \\
\hline MR grade $0-2$ & $49(82 \%)$ & $73(91 \%)$ & \\
\hline MR grade 3-4 & $11(18 \%)$ & $7(9 \%)$ & .112 \\
\hline
\end{tabular}

$M I$, Myocardial infarction; $C V A$, cerebrovascular accident; TIA, transient ischemic attack; $E F$, ejection fraction; NYHA, New York Heart Association; $M R$, mitral regurgitation. *Pulmonary complications: pneumonia, prolonged atelectasis, subcutaneous emphysema. †Major hospital morbidity: stroke, transmural myocardial infarction, revision for bleeding/tamponade, renal failure, respiratory failure, sepsis, deep wound infection. ఫॄEchocardiographic scale: 0 , none/trace; 1 , mild; 2 , moderate; 3 , moderate to severe; 4 , severe.

$3 \% / 2 \%$ had mild-to-moderate MR (grade 2-3) in the MS/ PA groups, respectively.

\section{Late Results}

This report covers a total follow-up of 385 patient-years (mean, $34 \pm 24$ months), which extended for up to 100 
Freedom from reoperation

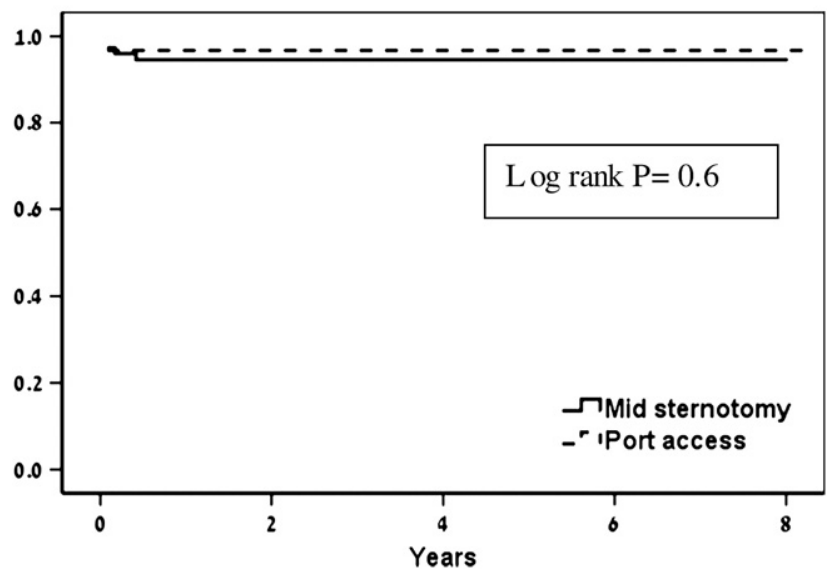

FIGURE 1. Kaplan-Meier curve for freedom from mitral valve reoperation in each group.

months, with a longer mean follow-up for the PA group (41 \pm 24 months) compared with the MS group $(28 \pm 22$ months, $P=.002)$. At follow-up, there were $3(4 \%)$ late deaths in the MS group (1 cardiac-related death [acute respiratory failure in a patient with severe MR], 1 sudden home death 5 years after surgical intervention, and $1 \mathrm{renal} / \mathrm{multi}$ organ failure-induced death 9 years after surgical intervention versus none in the PA group; $P=.13$ ).

Clinical follow-up was completed in $100 \%$ of the PA patient group and $96 \%$ of the MS group. In $2(2 \%)$ patients from the MS group, there was no late echocardiographic follow-up after hospital discharge. In patients lost to or without late echocardiographic follow-up, the latest observed data were used for data analysis.

At follow-up, NYHA functional class improved significantly in both groups, demonstrating no statistical difference between the groups $(P=.394)$.

Two (3\%) patients in the PA group required MV reoperation because of recurrent severe MR compared with $4(5 \%)$ patients in the MS group $\left(P=.637, \chi^{2}\right.$ test). Freedom from reoperation was $97 \%$ and $95 \%$ in the PA and MS groups, respectively $(P=.6, \log$-rank test; Figure 1$)$. In the PA group 6 patients underwent Alfieri stitching, of whom 2 underwent this technique as a bailout procedure. At follow-up, neither of them required reoperation; 1 had no MR, and 1 had residual grade 2 MR.

On multivariate analysis, we found that no preoperative or intraoperative variable (age, sex, preoperative NYHA class, surgical approach, repair technique, or cardiopulmonary bypass or aortic clamp times) was associated with increased risk for late valve reoperation.

Late echocardiographic follow-up revealed that 91\% (73/ 80 ) of patients in the MS group had no moderate or severe MR compared with $82 \%(49 / 60)$ of patients in the PA group $\left(P=.11, \chi^{2}\right.$ test; $P=.9, \log$-rank test; Figure 2$)$.
Freedom from moderate/sever MR

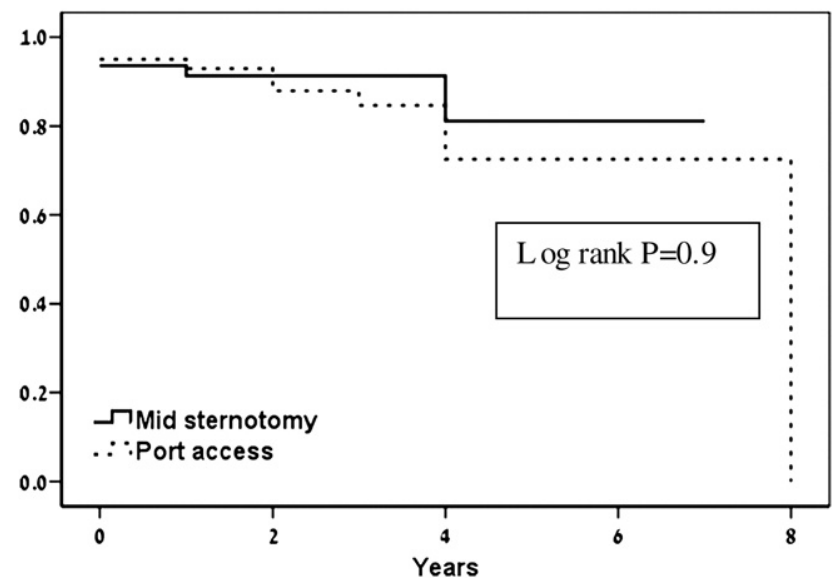

FIGURE 2. Kaplan-Meier curve for freedom from moderate or severe recurrent mitral valve regurgitation $(M R)$ in each group.

\section{DISCUSSION}

The PA approach for MV surgery was first introduced in $1996 .^{15,16}$ Initially, the advantages of this minimally invasive technique were overshadowed by the risks and complications associated with this approach. The major concerns included limited exposure of the MV, arterial injuries, difficulties in deairing the heart, and femoral cannulation complications. ${ }^{17}$

Improvements in technology and surgical instruments, routine use of transesophageal echocardiography in valve surgery, and increased surgical experience have all reduced the complication rate. Currently, in the hands of experienced surgeons, the minimally invasive approach is considered as safe as the standard MS approach, with several studies reporting on good early and long-term outcomes. $^{12}$

In this series we observed a higher rate of pulmonary complications in the PA group, in which 4 patients demonstrated radiographic evidence of partial right diaphragmatic elevation, suggesting possible phrenic nerve injury. None of them had any clinical respiratory problems, and their postoperative course was otherwise uneventful. Direct thermal injury might be the most plausible cause for right diaphragmatic elevation. As a result, we are now more careful and incise the pericardium at least 2 to $3 \mathrm{~cm}$ above the phrenic nerve. All other complications were similar between the groups, with no major complications related to the surgical technique (eg, aortic dissection in the PA group and mediastinitis in the MS group) occurring in either.

Long-term mortality was observed only in the MS group $(P=.13)$ and might be related to differences in preoperative characteristics (eg, higher NYHA class and more nonelective cases that were more prevalent in the MS group).

The advantages of minimally invasive MV repair through the PA approach must be weighed against the technical 
difficulties of repairing a valve with limited exposure. Two $(3 \%)$ patients in the PA group required reoperation of the MV compared with $4(5 \%)$ patients in the MS group $(P=.6)$.

In the early stage of the series of the PA group, the Alfieri edge-to-edge technique was used in 6 patients. This technique was chosen by the surgeon in 4 patients and as a bailout procedure in 2 patients to minimize operative time when the intraoperative echocardiographic result was unsatisfactory. For this particular group, mean follow-up was $65 \pm 22$ months. At follow-up, 4 patients had grade 0 or $1 \mathrm{MR}, 1$ patient had grade $3 \mathrm{MR}$, and 1 patient with grade $4 \mathrm{MR}$ underwent an MV repair reoperation. Although it seems that the use of the Alfieri technique did not significantly affect repair durability, the fact that it was used only in PA cases as a bailout procedure (in 2 patients) reflects the technical difficulty and learning curve needed in the minimally invasive approach.

We observed moderate or severe MR in $18 \%$ of patients in the PA group and $9 \%$ of patients in the MS group $(P=$ .11). These results suggest a trend toward a higher percentage of residual MR in the PA group, mainly because of a higher percentage of less optimal late results (MR grade $3)$ rather than a higher incidence of severe $\mathrm{MR}(P=.4)$. We are concerned by the fact that there are more patients with grade 3 MR in the PA group. However, we are unaware of existing data regarding the clinical significance and longterm effect of postrepair moderate MR. Of note, our initial results of PA in this series are reminiscent of typical mitral repair success rates with full sternotomy only a decade ago. All this supports the view that the obstacles of limited access might be overcome with more experience and refinements in technique.

Other authors have also reported excellent early and 1-year results of MV repair for the minimally invasive approach. ${ }^{13}$ However, their study was limited by a 1 -year follow-up without any comparison with an MS group. Our study demonstrates that minimally invasive repair for isolated posterior MV leaflet pathology can be performed safely. Early- and long-term clinical outcomes were equivalent to those of the standard MS approach. Echocardiographic results for the minimally invasive group approached those of the standard MS group.

Our series contains only isolated posterior leaflet flail or prolapse. It is anticipated that as more experience is gained, more complex cases (eg, anterior leaflet, bileaflet pathology, and endocarditis) will be performed using the minimally invasive approach. More complex MV repair in the minimally invasive approach appears to be safe and feasible. However, the quality and long-term durability of complex valve repair has not yet been clearly demonstrated. Patients with complex MV pathology who might be suitable for valve repair should still be carefully screened before opting for the minimally invasive approach.
This study is limited by its relatively small number of patients, its nonrandomized nature, and its limited follow-up period.

Selection approach was based on patient preference, surgeon preference, or both. Despite the fact that there was no significant difference between the groups in the type of MV pathology, there might have been some selection bias, with the surgeons offering the PA approach more strongly in cases in which the preoperative echocardiographic results anticipated an easier repair.

It would be necessary to evaluate a larger cohort of patients with a longer follow-up period to reach more definite conclusions regarding the comparability between the 2 approaches.

We thank Maya First for her expert statistical analysis and Vivienne York for her valuable editorial assistance.

\section{References}

1. Avierinos JF, Gersh BJ, Melton LJ 3rd, Bailey KR, Shub C, Nishimura RA, et al. Natural history of asymptomatic mitral valve prolapse in the community. Circulation. 2002;106:1355-61.

2. Gillinov AM, Cosgrove DM 3rd. Current status of mitral valve repair. Am Heart Hosp J. 2003; 1:47-54.

3. Mohty D, Orszulak TA, Schaff HV, Avierinos JF, Tajik JA, Enriquez-Sarano M. Very long-term survival and durability of mitral valve repair for mitral valve prolapse. Circulation. 2001;104(suppl 1):I1-7.

4. Suri RM, Schaff HV, Dearani JA, Sundt TM 3rd, Daly RC, Mullany CJ, et al. Survival advantage and improved durability of mitral repair for leaflet prolapse subsets in the current era. Ann Thorac Surg. 2006;82:819-26.

5. Enriquez-Sarano M, Orszulak TA, Schaff HV, Abel MD, Tajik AJ, Frye RL. Mitral regurgitation: a new clinical perspective. Mayo Clin Proc. 997;72:1034-43.

6. Grossi EA, La Pietra A, Galloway AC, Colvin SB. Videoscopic mitral valve repair and replacement using the port access technique. Adv Card Surg. 2001; 13:77-88

7. Gundry SR, Shattuck OH, Razzouk AJ, del Rio MJ, Sardari FF, Bailey LL. Facile minimally invasive cardiac surgery via mini sternotomy. Ann Thorac Surg. 1998; 65:1100-4.

8. Nair RU, Sharpe DA. Limited lower sternotomy for minimally invasive mitral valve replacement. Ann Thorac Surg. 1998;65:273-4.

9. Gillinov AM, Banbury MK, Cosgrove DM. Hemisternotomy approach for aortic and mitral valve surgery. J Card Surg. 2000;15:15-20.

10. Cohn LH, Adams DH, Couper GS, Bichell DP, Rosborough DM, Sears SP, et al. Minimally invasive cardiac valve surgery improves patient satisfaction while reducing costs of cardiac valve replacement and repair. Ann Surg. 1997;226:421-8.

11. Cosgrove DM 3rd, Sabik JF, Navia JL. Minimally invasive valve operations. Ann Thorac Surg. 1998;65:1535-89.

12. Modi P, Hassan A, Chitwood WR Jr. Minimally invasive mitral valve surgery: a systematic review and meta-analysis. Eur J Cardiothorac Surg. 2008;34:943-52.

13. Grossi EA, LaPietra A, Ribakove GH, Delianides J, Esposito R, Culliford AT, et al. Minimally invasive versus sternotomy approaches for mitral reconstruction: comparison of intermediate-term results. J Thorac Cardiovasc Surg. 2001;121: 708-13.

14. Akins CW, Miller DC, Turina MI, Kouchoukos NT, Blackstone EH, Grunkemeier GL, et al. Guidelines for reporting mortality and morbidity after cardiac valve interventions. $J$ Thorac Cardiovasc Surg. 2008;135:732-8.

15. Stevens JH, Burdon TA, Peters WS, Siegel LC, Pompili MF, Vierra MA, et al. Port-access coronary artery bypass grafting: a proposed surgical method. J Thorac Cardiovasc Surg. 1996;111:567-73.

16. Stevens JH, Burdon TA, Siegel LC, Peters WS, Pompili MF, St Goar FG, et al. Port-access coronary artery bypass with cardioplegic arrest: acute and chronic canine studies. Ann Thorac Surg. 1996;62:435-41.

17. Mohr FW, Falk V, Diegeler A, Walther T, van Son JA, Autschbach R. Minimally invasive port-access mitral valve surgery. J Thorac Cardiovasc Surg. 1998;115: 567-76. 